\title{
Effects of denosumab on bone metabolism and bone mineral density with anti-TNF inhibitors, tocilizumab, or abatacept in osteoporosis with rheumatoid arthritis
}

This article was published in the following Dove Press journal:

Therapeutics and Clinical Risk Management

\author{
Takako Suzuki' \\ Yukio Nakamura ${ }^{1,2}$ \\ Hiroyuki Kato' \\ 'Department of Orthopaedic \\ Surgery, Shinshu University School of \\ Medicine, Matsumoto, ${ }^{2}$ Department \\ of Orthopedic Surgery, Showa-Inan \\ General Hospital, Komagane, Japan
}

Correspondence: Yukio Nakamura Department of Orthopaedic Surgery, Shinshu University School of Medicine, Asahi 3-I-I, Matsumoto 390-862I, Japan Tel +8I 263372659

Fax +8I 263358844

Email yxn I4@aol.jp

\begin{abstract}
Introduction: The aim of this 18-month retrospective study was to evaluate the differences in outcomes of denosumab with tumor necrosis factor (TNF) inhibitors (TNFis), tocilizumab (TCZ), or abatacept (ABT) treatment in osteoporosis (OP) patients with rheumatoid arthritis (RA).

Patients and methods: Patients were divided into TNFis-treated (TNF group; 44 cases), TCZ-treated (TCZ group; 8 cases), or ABT-treated (ABT group; 14 cases) groups. We measured serum bone-specific alkaline phosphatase (BAP) and tartrate-resistant acid phosphatase $5 \mathrm{~b}$ (TRACP-5b) at baseline and every 3 months for 18 months and assessed bone mineral density (BMD) of the lumbar 1-4 vertebrae (L-BMD) and total hip BMD (H-BMD) at baseline and every 6 months for 18 months.

Results: There were no significant differences in the percent changes in BAP, TRACP-5b, or L-BMD among the groups. The percent change in H-BMD was significantly increased in the TCZ group at 12 months or at 12 and 18 months, compared with that in the ABT group or TNF group, respectively. The percent change in L-BMD was significantly increased at 12 months in the TCZ and TNF groups, and at 18 months in all the 3 groups compared with pretreatment levels, whereas the percent change in H-BMD was significantly higher at 6, 12, and 18 months in the TCZ group, at 12 and 18 months in the TNF group, and at 18 months in the ABT group, compared with pretreatment levels.
\end{abstract}

Conclusion: Our findings suggest that TCZ might be more useful than TNF or ABT in light of the observed H-BMD increases with denosumab therapy for OP patients with RA.

Keywords: abatacept, denosumab, rheumatoid arthritis, TNF inhibitors, tocilizumab

\section{Introduction}

Osteoporosis (OP) is a chronic metabolic disease characterized by the progressive loss of bone mass and microarchitectural deterioration that can increase the risk of fragility fractures. Although bisphosphonates (BPs) are the first-line drugs for treating OP, ${ }^{1}$ recent trials have demonstrated the efficacy of other anti-resorption drugs, such as denosumab, that are effective for primary and secondary OP treatments. ${ }^{2-4}$ Denosumab is a humanized monoclonal antibody that blocks the receptor activator for nuclear factor $\kappa \mathrm{B}$ ligand (RANKL) to potently repress bone resorption. ${ }^{5}$ Bone et $\mathrm{al}^{2}$ have reported that denosumab therapy for up to 10 years was related to low rates of adverse events and fractures, and denosumab continued to increase bone mineral density (BMD) in the multicenter, randomized, double-blind, placebo-controlled, Phase III FREEDOM trial of postmenopausal women aged 60-90 years with OP. We and others have also 
described denosumab as useful in improving bone metabolism and increasing BMD. ${ }^{3-6}$ Thus, denosumab represents a good option to treat OP in routine medical practice.

Rheumatoid arthritis (RA) is a chronic, inflammatory condition with progressive and systemic inflammation resulting in joint destruction and functional disability. RA is the primary risk factor for OP and predisposes patients to an increased risk of fractures. Currently, the overall management of OP patients with RA is inadequate in clinical practice, which is a major concern in rheumatology. ${ }^{3,7,8}$ Thus, efficacy on the treatment of OP complicated with RA is urgently required.

Cytokines such as tumor necrosis factor (TNF) and RANKL and antibodies to citrullinated protein antigens act directly on osteoclasts. ${ }^{9,10}$ Currently, several biological disease-modifying antirheumatic drugs (bDMARDs) are also available for RA treatment. bDMARDs are broadly classified according to their target molecules into TNF inhibitors (TNFis; infliximab [IFX], etanercept [ETN], adalimumab [ADA], certolizumab pegol [CP], and golimumab [GLM]) and non-TNFis (tocilizumab [TCZ], an interleukin-6 [IL-6] inhibitor, and abatacept [ABT], a bDMARD-targeting CD80/ CD86 on T cells). Increasing evidence has shown that TNFis and non-TNFis remain the most efficacious therapy for RA. Although Hasegawa et $\mathrm{al}^{11}$ have recently found that denosumab plus bDMARDs had additive effects on the suppression of structural bone damage, there have been no studies comparing TNFis and non-TNFis during denosumab therapy in OP patients with RA.

This investigation examined the differences in bone metabolism and BMD among TNFis, TCZ, and ABT during denosumab therapy for OP patients with RA.

\section{Patients and methods}

\section{Patient selection}

Sixty-six Japanese female OP patients with RA were recruited at the Shinshu University School of Medicine and Showa-Inan General Hospital between 2014 and 2017 and were summarized in Table 1 . The subjects were classified into TNFis cases (TNF group; 44 cases) or cases treated with TCZ (TCZ group; 8 cases) or ABT (ABT group; 14 cases) matched on the basis of age, gender, body mass index, RA duration, and disease activity (Table 1). Alendronate (ALN), risedronate (RIS), and minodronate (MIN) had been used in various regimens as long-term BP pretreatment. We did not examine the effects of individual BP drugs as they were routinely changed when exhibiting low responsiveness. BPs were substituted with denosumab just before denosumab therapy in the BP pretreated patients.
Table I Patient characteristics before denosumab therapy

\begin{tabular}{|c|c|c|c|}
\hline Characteristic & $\begin{array}{l}\text { TNF } \\
\text { group } \\
(n=44)\end{array}$ & $\begin{array}{l}\text { TCZ } \\
\text { group } \\
(n=8)\end{array}$ & $\begin{array}{l}\text { ABT } \\
\text { group } \\
(n=14)\end{array}$ \\
\hline Age (years) & $67.5 \pm 1.0$ & $67.6 \pm 2.6$ & $70.4 \pm 2.2$ \\
\hline Gender (F:M) & $44: 0$ & $8: 0$ & $14: 0$ \\
\hline BMI $\left(\mathrm{kg} / \mathrm{m}^{2}\right)$ & $20.5 \pm 0.5$ & $21.6 \pm 1.6$ & $20.4 \pm 1.1$ \\
\hline Disease duration (years) & $5.9 \pm 0.7$ & $6.7 \pm 1.0$ & $6.1 \pm 0.9$ \\
\hline \multicolumn{4}{|l|}{ Biologic DMARDs (n) } \\
\hline Infliximab & 14 & & \\
\hline Etanercept & 15 & & \\
\hline Adalimumab & 7 & & \\
\hline Golimumab & 6 & & \\
\hline Certolizumab pegol & 2 & & \\
\hline Methotrexate use (n) & 39 & 5 & 10 \\
\hline Methotrexate dose (mg/week) & $7.3 \pm 0.5$ & $8.4 \pm 1.5$ & $7.3 \pm 1.2$ \\
\hline Prednisolone use (n) & 10 & 4 & 5 \\
\hline Prednisolone dose (mg/day) & $6.1 \pm 1.1$ & $5.0 \pm 0.7$ & $6.2 \pm 1.0$ \\
\hline DAS28CRP & $3.4 \pm 0.1$ & $3.3 \pm 0.6$ & $3.5 \pm 0.4$ \\
\hline CDAI & $13.3 \pm 1.2$ & $14.9 \pm 3.8$ & $13.9 \pm 2.5$ \\
\hline HAQ-DI & $0.9 \pm 0.1$ & $1.0 \pm 0.3$ & $\mathrm{I} . \mathrm{I} \pm 0.4$ \\
\hline MMP-3 (IU/mL) & $93.1 \pm 22.5$ & $85.0 \pm 16.7$ & $94.5 \pm 21.9$ \\
\hline $\begin{array}{l}\text { Serum albumin-corrected } \\
\text { calcium }(\mathrm{mg} / \mathrm{dL})\end{array}$ & $9.4 \pm 0.1$ & $9.4 \pm 0.1$ & $9.3 \pm 0.1$ \\
\hline Serum phosphorus (mg/dL) & $3.4 \pm 0.1$ & $3.4 \pm 0.1$ & $3.4 \pm 0.1$ \\
\hline Serum BAP $(\mu g / L)$ & $14.7 \pm 1.2$ & $13.6 \pm 2.1$ & $14.1 \pm 1.8$ \\
\hline Serum TRACP-5b (mU/dL) & $280.6 \pm 23.7$ & $245.8 \pm 53.5$ & $249.8 \pm 42.1$ \\
\hline $\begin{array}{l}\text { Urinary NTX (nmol BCE/ } \\
\text { mmol/CRE) }\end{array}$ & $42.3 \pm 4.6$ & $42.4 \pm 9.9$ & \\
\hline Serum whole PTH (pg/mL) & $24.0 \pm 2.1$ & $21.3 \pm 2.7$ & $22.1 \pm 2.4$ \\
\hline Serum $1,25(\mathrm{OH})_{2} \mathrm{D}_{3}(\mathrm{pg} / \mathrm{mL})$ & $43.2 \pm 2.5$ & $34.8 \pm 5.4$ & $41.2 \pm 4.2$ \\
\hline BP use $(n)$ & 29 & 5 & 8 \\
\hline BP period (years) & $4.3 \pm 0.3$ & $4.6 \pm 0.9$ & $4.5 \pm 0.6$ \\
\hline Lumbar I-4 BMD $\left(\mathrm{g} / \mathrm{cm}^{2}\right)$ & $0.777 \pm 0.02$ & $0.783 \pm 0.06$ & $0.773 \pm 0.06$ \\
\hline Total hip BMD $\left(\mathrm{g} / \mathrm{cm}^{2}\right)$ & $0.575 \pm 0.02$ & $0.566 \pm 0.04$ & $0.580 \pm 0.04$ \\
\hline
\end{tabular}

Abbreviations: $A B T$, abatacept; BAP, bone-specific alkaline phosphatase; $\mathrm{BMD}$, bone mineral density; BMI, body mass index; $\mathrm{BP}$, bisphosphonate; CDAI, Crohn's disease activity index; DAS28CRP, disease activity score 28 C-reactive protein; DMARDs, disease-modifying antirheumatic drugs; F, female; HAQ$\mathrm{DI}$, health assessment questionnaire disability index; M, male; MMP-3, matrix metalloproteinase-3; NTX, type I collagen cross-linked N-telopeptide; PTH, parathyroid hormone; TCZ, tocilizumab; TNF, tumor necrosis factor; TRACP-5b, tartrate-resistant acid phosphatase 5 b.

The inclusion criteria for this 18-month retrospective study were OP patients with low T-score in total hip BMD (H-BMD) and/or lumbar 1-4 BMD (L-BMD; ie, less than -2.5 SD) with RA. Exclusion criteria were patients with chronic renal failure (estimated glomerular filtration rate $<40 \mathrm{~mL} / \mathrm{min} / 1.73 \mathrm{~m}^{2}$ ), OP-affecting bone metabolic disorders or diabetes mellitus, and fracture within 1 year prior to the study. The diagnosis of OP was based on the revised criteria established by the Japanese Society of Bone and Mineral Research. ${ }^{12}$ The diagnosis and treatment of RA were conducted following the 2010 American 
College of Rheumatology (ACR)/European League Against Rheumatism (EULAR) classification system. ${ }^{13}$

This study was approved by the Institutional Ethical Review Board of Shinshu University School of Medicine, Japan, before its commencement. Written informed consent was obtained from all patients. All study methods were carried out in accordance with the approved guidelines.

\section{Measurement of RA state indicator, matrix metalloproteinase-3 (MMP-3)}

All serological measurements including MMP-3 (Kyowa Pharma Chemicals, Toyama, Japan), were performed prior to the treatment by SRL Inc. (Tokyo, Japan). All data are expressed as the mean \pm standard error.

\section{Treatment plan}

Each patient received denosumab (60 mg subcutaneously) at baseline and once every 6 months in all groups. We administered vitamin D supplementation tablets $(762.5 \mathrm{mg}$ of precipitated calcium carbonate, $200 \mathrm{IU}$ of cholecalciferol, and $59.2 \mathrm{mg}$ of magnesium carbonate) twice daily to all patients during denosumab administration.

\section{Measurement of bone turnover markers}

Serum calcium was measured by arsenazo reaction and phosphorus was measured by molybdate reaction. Serum active form of vitamin $\mathrm{D}\left(1,25(\mathrm{OH})_{2} \mathrm{D}_{3}\right)$ and whole parathyroid hormone (PTH) were measured by an immunoradiometric assay. Serum bone-specific alkaline phosphatase (BAP) was measured as a bone formation marker using a chemiluminescent enzyme immunoassay (CLEIA; Beckman Coulter Inc., Tokyo, Japan). Serum tartrate-resistant acid phosphatase-5b (TRACP-5b) (Osteomark; Osteox International, Seattle, WA) was assessed as a marker of bone resorption by ELISA. All measurements were performed by SRL Inc. (Tokyo, Japan). All serum samples were stored at $-80^{\circ} \mathrm{C}$ until assessment at the end of the study. Samples were collected before denosumab treatment and at $3,6,9,12,15$, and 18 months of therapy.

\section{BMD measurement}

BMD was measured using a dual-energy $\mathrm{X}$-ray absorption fan-beam bone densitometer (Lunar Prodigy; GE Healthcare Bio-Sciences Corp., Piscataway, NJ, USA) for lumbar 1-4 of the posteroanterior spine and bilateral total hips. $\mathrm{H}-\mathrm{BMD}$ was calculated as the mean BMD of the right and left hips. BMD was assessed before denosumab treatment and at 6,12 , and 18 months.

\section{Statistics}

In all groups, the percent changes in markers and BMD were determined at the indicated time points using Bonferroni correction for multiple comparisons. Marker and BMD comparisons among the groups were performed by the KruskalWallis test; $p<0.05$ was considered statistically significant.

\section{Results}

Table 1 presents the patients' characteristics prior to the study.

\section{Serum albumin-corrected calcium, serum phosphorus, serum whole PTH, and I, $25(\mathrm{OH})_{2} \mathrm{D}_{3}$}

There were no significant differences in the percent changes in serum albumin-corrected calcium (Figure 1A), serum phosphorus (Figure 1B), whole PTH (Figure 1C), or 1,25(OH) ${ }_{2} \mathrm{D}_{3}$ (Figure 1D) among the groups. No significant difference was detected in the percent change of any value compared with baseline levels (Figure 1A-D).

\section{Bone turnover markers}

There were no significant differences in the percent changes in BAP or TRACP-5b among the groups (Figure 2A and B).

Compared with pretreatment levels, the percent change in BAP in the TNF group showed significant differences at every time point ( $p<0.01$ at $3,9,12,15$, and 18 months and $p<0.05$ at 6 months); however, there was no significant difference of BAP in the TCZ or ABT group, respectively (Figure 2A).

Compared with pretreatment levels, the percent changes in TRACP-5b in the TNF group and the TCZ group showed significant differences at every time point $(p<0.01$ in both groups; Figure 2B).

\section{BMD measurements}

There was no significant difference in the percent change in L-BMD among the groups. The percent change in L-BMD was significantly increased at 12 and 18 months in the TNF group ( $p<0.01)$, at 18 months in the ABT group $(p<0.05)$, and at 12 and 18 months ( $p<0.05$ and $p<0.01$, respectively) in the TCZ group versus baseline values (Figure 2C).

The percent change in $\mathrm{H}-\mathrm{BMD}$ was significantly increased at 6,12 , and 18 months in the TCZ group $(p<0.01)$, at 12 and 18 months in the TNF group $(p<0.01)$, and at 18 months in the ABT group $(p<0.01)$ compared with pretreatment 
A Serum albumin-corrected calcium

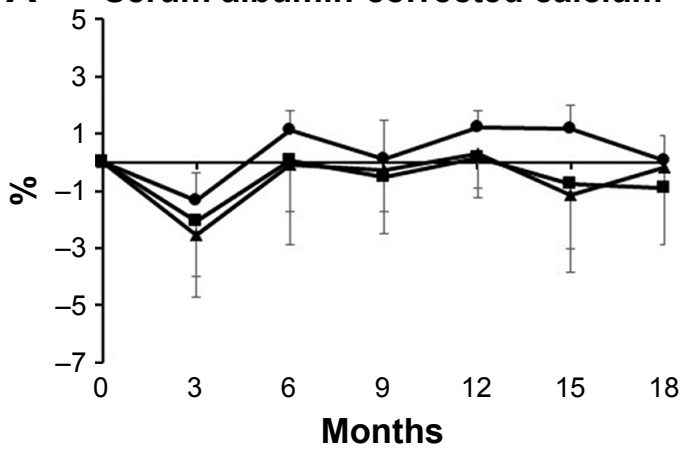

C

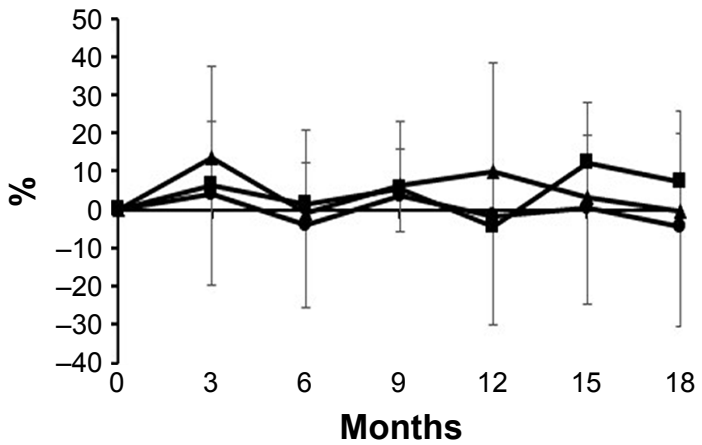

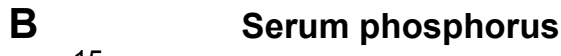

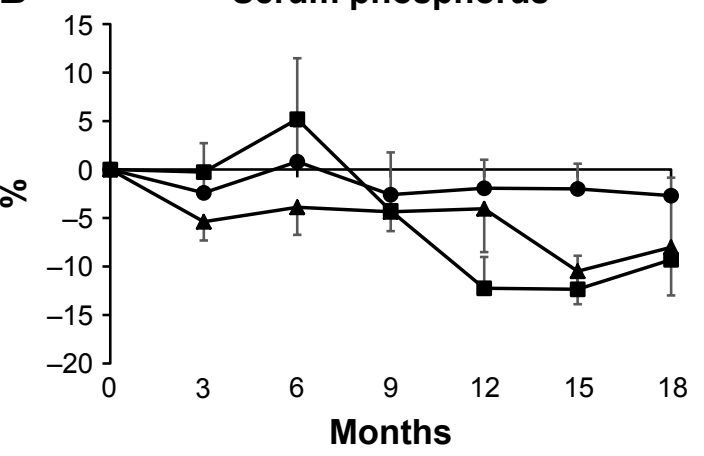

D $\quad 1,25(\mathrm{OH})_{2} \mathrm{D}_{3}$

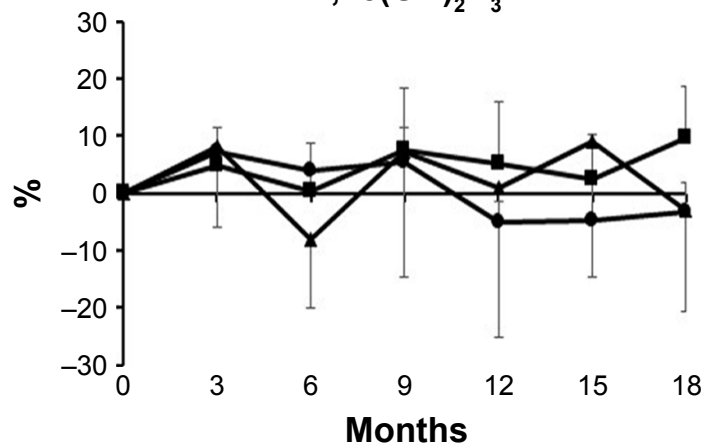

Figure I Percent changes of calcium metabolism for 18 months after denosumab therapy.

Notes: Percent changes in serum albumin-corrected calcium $(\mathbf{A})$, serum phosphorus $(\mathbf{B})$, serum whole PTH $(\mathbf{C})$, and serum I,25(OH) ${ }_{2} \mathrm{D}_{3}(\mathbf{D})$ for the 18 -month study period. Circles show the TNF group, triangles show the TCZ group, and rectangles show the ABT group.

Abbreviations: ABT, abatacept; PTH, parathyroid hormone; TCZ, tocilizumab; TNF, tumor necrosis factor inhibitors.

A

BAP

Months

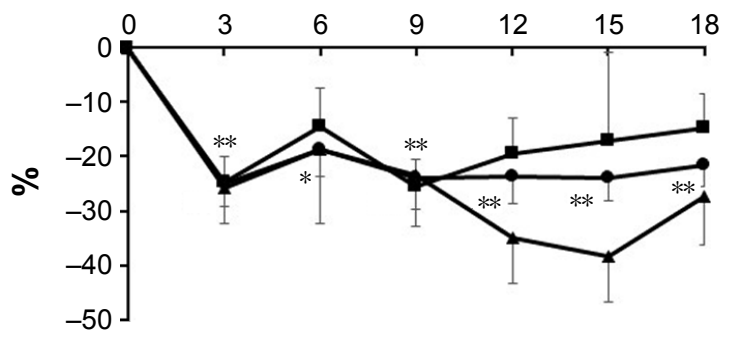

C

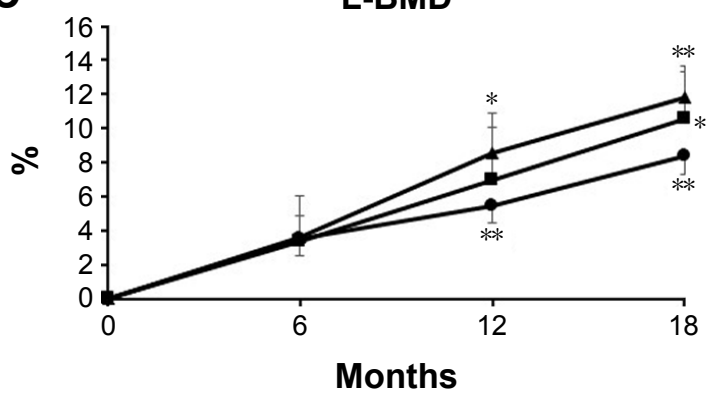

B

TRACP-5b

\section{Months}

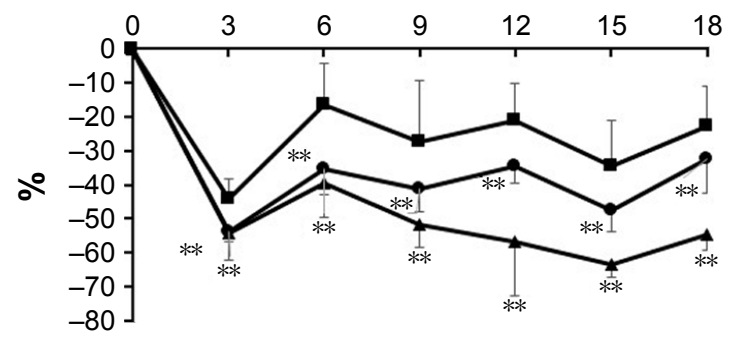

D

H-BMD

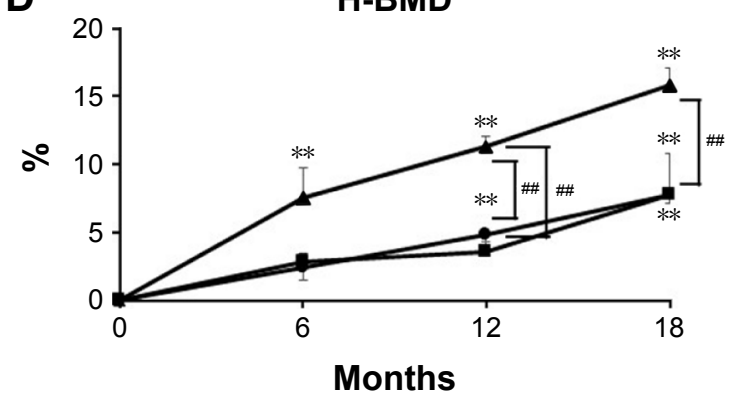

Figure 2 Percent changes of bone metabolic markers and bone mineral density for 18 months after denosumab therapy.

Notes: Percent changes in serum BAP (A) and serum TRACP-5b (B) for the 18-month study period. Percent changes in L-BMD (C) and H-BMD (D) for the I8-month study period. Circles show the TNF group, triangles show the TCZ group, and rectangles show the ABT group. $* p<0.05$ and $* * p<0.01$ denote significant differences compared with pretreatment in the TNF, TCZ, or ABT groups. ${ }^{\#}<<0.0$ I shows significant differences between the groups at each time point.

Abbreviations: ABT, abatacept; BAP, bone-specific alkaline phosphatase; BMD, bone mineral density; H-BMD, hip bone mineral density; L-BMD, lumbar bone mineral density; TCZ, tocilizumab; TNF, tumor necrosis factor inhibitors; TRACP-5b, tartrate-resistant acid phosphatase $5 \mathrm{~b}$. 
levels. Among the groups, there were significant differences between the TNF and TCZ groups $(p<0.01)$ and the ABT and TCZ groups $(p<0.01)$ at 12 months. There was also a significant difference between the TNF and TCZ groups $(p<0.01)$ at 18 months (Figure 2D).

\section{Discussion}

To our knowledge, this is the first report examining the differences in bone metabolism and BMD among TNFis, TCZ, and $\mathrm{ABT}$ in $\mathrm{OP}$ patients with RA under denosumab therapy. The percent change in $\mathrm{H}-\mathrm{BMD}$ was significantly higher in the TCZ group than the TNF and ABT groups at 12 months and the TNF group at 18 months. No remarkable differences in bone turnover markers or percent changes in L-BMD were detected among the groups.

An important goal in RA therapy, particularly, complicated with OP, is the improvement of bone metabolism and BMD because bone quality is considered to decline in RA. ${ }^{14}$ Among OP drugs, denosumab is considered a good treatment option in OP patients with RA owing to gains in bone turnover markers and $\mathrm{BMD}^{3,6}$ although there is a consensus that denosumab does not suppress RA activity. ${ }^{15,16}$

There exist no direct comparisons of bone metabolism under TNFis or non-TNFis during denosumab therapy in OP patients with RA to date. This study revealed that denosumab significantly increased the percent change in H-BMD in the TCZ group compared with that in the TNF and ABT groups. The mechanism by which denosumab plus TCZ imparted greater effects over the other drugs may include the following factors: 1) the differentiation of osteoclasts in the presence of IL-6 and soluble IL-6 receptor was suppressed under TCZ addition via the inhibition of RANKL induction, however, those findings were not observed in the presence of TNF or IL-17 in fibroblast-like synovial cells from RA patients ${ }^{17}$ suggesting that TCZ might be potentially able to inhibit osteoclastogenesis in a greater extent than the other biologics, and 2) the percent change in TRACP-5b shown in Figure 2B suggested the enhanced suppression of bone resorption in the TCZ group than in the TNF or ABT group.

Progressive joint degeneration is a hallmark of RA. Adami et $\mathrm{al}^{18}$ reported that TNFis could prevent bone erosion and OP via an increase in serum PTH in RA patients. Recently, Zerbini et $\mathrm{al}^{19}$ reviewed that in RA patients, 1) the treatment with biologics was associated with the decrease in bone loss, 2) TNFis showed preservation or increase in L-BMD and $\mathrm{H}-\mathrm{BMD}$, and a better profile of bone markers. Here, bone markers were significantly suppressed by denosumab, and thus, BMD might have significantly increased. IFX has been used in the most aforementioned studies with few investigations on TCZ and ABT to date. ${ }^{19}$ Smolen et $\mathrm{al}^{20}$ reported on the progression of joint damage in RA patients treated with methotrexate (MTX) versus those with IFX plus MTX. Combination of IFX and MTX suppressed radiographic progression irrespective of baseline disease activity or joint damage. ${ }^{20}$ Emery et $\mathrm{al}^{21}$ described that in the combination of MTX and ETN in active early RA (COMET) trial, radiographic nonprogression was achievable in RA patients within 1 year of treatment. The PREMIER and HOPEFUL-1 studies revealed that combination therapy with ADA plus MTX was significantly superior to either MTX or ADA alone in inhibiting radiographic progression in early and active RA patients, ${ }^{22,23}$ whereas the GO-FORTH study showed GLM and MTX to be significantly more effective than MTX monotherapy in limiting the radiographic progression. ${ }^{24}$ In the C-OPERA study of MTX-naive early RA patients with poor prognostic factors, CP and MTX significantly suppressed structural damage. ${ }^{25}$ These data collectively indicate that TNFis, especially in combination with MTX, may prevent bone damage and joint destruction in RA. Meanwhile, IL-6 is partly responsible for the promotion of joint destruction in RA patients, thus TCZ, an anti-IL-6 receptor antibody, likely inhibits joint damage in RA through this mechanism. ${ }^{26,27}$ The 2-year outcome of the AGREE study showed that treatment with ABT plus MTX produced greater inhibition of radiographic progression than did MTX alone. ${ }^{28}$ Roser-Page et $\mathrm{al}^{29}$ observed that ABT could increase bone formation via the enhancement of Wnt10b production in mice, indicating that ABT potentially improved OP in humans.

Finally, Orsolini et al ${ }^{30}$ reported that TNFis in RA caused an early increase in bone turnover markers to decrease H-BMD, whereas Kume et $\mathrm{al}^{31}$ described that TCZ maintained BMD in OP but increased BMD in osteopenia in RA patients. Thus, it is still controvertial whether or not TNFis or non-TNFis themselves could improve OP in RA. This study showed that both BMD and bone metabolism were ameliorated by denosumab therapy and that the TCZ better improved H-BMD than did TNFis or ABT. Taken together, denosumab plus TCZ might be a better option for OP in RA for biologic use.

The main limitations of this study were its small sample size and retrospective design. A long-term observational period also will be required to clarify if BMD and bone metabolism increases are maintained by denosumab.

\section{Conclusion}

To our knowledge, this is the first report on differences of bone metabolism and BMD among TNFis, TCZ, and ABT in OP patients with RA during denosumab therapy. The percent 
change in H-BMD was significantly higher in the TCZ group over the TNF and ABT groups at 12 months and over the TNF group at 18 months. No remarkable differences in bone turnover markers or percent changes in L-BMD were detected among the groups. Thus, denosumab is a useful agent to improve H-BMD in the TCZ group than in the TNF or ABT group in OP patients with RA during denosumab therapy. Since the main limitations of this study were its small sample size and retrospective design, further studies will be required to confirm our findings.

\section{Disclosure}

The authors report no conflicts of interest in this work.

\section{References}

1. McClung M, Harris ST, Miller PD, et al. Bisphosphonate therapy for osteoporosis: benefits, risks, and drug holiday. Am J Med. 2013; 126(1):13-20.

2. Bone HG, Wagman RB, Brandi ML, et al. 10 Years of denosumab treatment in postmenopausal women with osteoporosis: results from the phase 3 randomised FREEDOM trial and open-label extension. Lancet Diabetes Endocrinol. 2017;5(7):513-523.

3. Nakamura Y, Suzuki T, Yoshida T, Yamazaki H, Kato H. Vitamin D and calcium are required during denosumab treatment in osteoporosis with rheumatoid arthritis. Nutrients. 2017;9(5):E428.

4. Suzuki T, Nakamura Y, Tanaka M, et al. Comparison of the effects of denosumab with either active vitamin $\mathrm{D}$ or native vitamin $\mathrm{D}$ on bone mineral density and bone turnover markers in postmenopausal osteoporosis. Mod Rheumatol. Epub 2017 Apr 11:1-4.

5. McClung M. Role of RANKL inhibition in osteoporosis. Arthritis Res Ther. 2007;9(Suppl 1):S3. Review.

6. Kinoshita H, Miyakoshi N, Kashiwagura T, Kasukawa Y, Sugimura Y, Shimada Y. Comparison of the efficacy of denosumab and bisphosphonates for treating secondary osteoporosis in patients with rheumatoid arthritis. Mod Rheumatol. 2017;27(4):582-586.

7. Lee SG, Park YE, Park SH, et al. Increased frequency of osteoporosis and BMD below the expected range for age among South Korean women with rheumatoid arthritis. Int J Rheum Dis. 2012;15(3):289-296.

8. Kim SY, Schneeweiss S, Liu J, et al. Risk of osteoporotic fracture in a large population-based cohort of patients with rheumatoid arthritis. Arthritis Res Ther. 2010;12(4):R154.

9. Roux S, Orcel P. Bone loss. Factors that regulate osteoclast differentiation: an update. Arthritis Res. 2000;2:451-456.

10. Ilani AA, Mackworth-Young CG. The role of citrullinated protein antibodies in predicting erosive disease in rheumatoid arthritis: a systematic literature review and meta-analysis. Int J Rheumatol. 2015; 2015:728610.

11. Hasegawa T, Kaneko Y, Izumi K, Takeuchi T. Efficacy of denosumab combined with bDMARDs on radiographic progression in rheumatoid arthritis. Joint Bone Spine. 2017;84:379-380.

12. Soen S. New diagnostic criteria and guidelines on osteoporosis. Diagnostic criteria for primary osteoporosis: year 2012 revision. Clin Calcium. 2014;24:323-329. (Article in Japanese).

13. van der Linden MP, Knevel R, Huizinga TW, van der Helm-van Mil AH. Classification of rheumatoid arthritis: comparison of the 1987 American College of Rheumatology criteria and the 2010 American College of Rheumatology/European League Against Rheumatism criteria. Arthritis Rheum. 2011;63(1):37-42.

14. Shimizu T, Takahata M, Kimura-Suda H, et al. Autoimmune arthritis deteriorates bone quantity and quality of periarticular bone in a mouse model of rheumatoid arthritis. Osteoporos Int. 2017;28(2):709-718.
15. Mochizuki T, Yano K, Ikari K, et al. Effects of denosumab treatment on bone mineral density and joint destruction in patients with rheumatoid arthritis. J Bone Miner Metab. Epub 2017 Jul 5:doi:10.1007/s00774017-0848-1.

16. Nakamura Y, Suzuki T, Kato H. Denosumab significantly improves bone mineral density with or without bisphosphonate pre-treatment in osteoporosis with rheumatoid arthritis: denosumab improves bone mineral density in osteoporosis with rheumatoid arthritis. Arch Osteoporos. 2017;12(1):80.

17. Hashizume M, Tan SL, Takano J, et al. Tocilizumab, a humanized anti-IL-6R antibody, as an emerging therapeutic option for rheumatoid arthritis: molecular and cellular mechanistic insights. Int Rev Immunol. 2015;34(3):265-279.

18. Adami G, Orsolini G, Adami S, et al. Effects of TNF inhibitors on parathyroid hormone and Wnt signaling antagonists in rheumatoid arthritis. Calcif Tissue Int. 2016;99(4):360-364.

19. Zerbini CAF, Clark P, Mendez-Sanchez L, et al; IOF Chronic Inflammation and Bone Structure (CIBS) Working Group. Biologic therapies and bone loss in rheumatoid arthritis. Osteoporos Int. 2017; 28(2):429-446.

20. Smolen JS, Van Der Heijde DM, St Clair EW, et al; Active-Controlled Study of Patients Receiving Infliximab for the Treatment of Rheumatoid Arthritis of Early Onset (ASPIRE) Study Group. Predictors of joint damage in patients with early rheumatoid arthritis treated with high-dose methotrexate with or without concomitant infliximab: results from the ASPIRE trial. Arthritis Rheum. 2006;54:702-710.

21. Emery P, Breedveld FC, Hall S, et al. Comparison of methotrexate monotherapy with a combination of methotrexate and etanercept in active, early, moderate to severe rheumatoid arthritis (COMET): a randomised, double-blind, parallel treatment trial. Lancet. 2008;372(9636): 375-382.

22. Breedveld FC, Weisman MH, Kavanaugh AF, et al. The PREMIER study: a multicenter, randomized, double-blind clinical trial of combination therapy with adalimumab plus methotrexate versus methotrexate alone or adalimumab alone in patients with early, aggressive rheumatoid arthritis who had not had previous methotrexate treatment. Arthritis Rheum. 2006;54(1):26-37.

23. Yamanaka $\mathrm{H}$, Ishiguro $\mathrm{N}$, Takeuchi $\mathrm{T}$, et al. Recovery of clinical but not radiographic outcomes by the delayed addition of adalimumab to methotrexate-treated Japanese patients with early rheumatoid arthritis: 52-week results of the HOPEFUL-1 trial. Rheumatology (Oxford). 2014; 53:904-913.

24. Tanaka Y, Harigai M, Takeuchi T, et al; GO-FORTH Study Group. Golimumab in combination with methotrexate in Japanese patients with active rheumatoid arthritis: results of the GO-FORTH study. Ann Rheum Dis. 2012;71(6):817-824.

25. Atsumi T, Yamamoto K, Takeuchi T, et al. The first double-blind, randomised, parallel-group certolizumab pegol study in methotrexatenaive early rheumatoid arthritis patients with poor prognostic factors, C-OPERA, shows inhibition of radiographic progression. Ann Rheum Dis. 2016;75(1):75-83.

26. Kotake S, Sato K, Kim KJ, et al. Interleukin-6 and soluble interleukin-6 receptors in the synovial fluids from rheumatoid arthritis patients are responsible for osteoclast-like cell formation. J Bone Miner Res. 1996; 11(1):88-95.

27. Smolen JS, Beaulieu A, Rubbert-Roth A, et al; OPTION Investigators. Effect of interleukin-6 receptor inhibition with tocilizumab in patients with rheumatoid arthritis (OPTION study): a double-blind, placebocontrolled, randomised trial. Lancet. 2008;371(9617):987-997.

28. Bathon J, Robles M, Ximenes AC, et al. Sustained disease remission and inhibition of radiographic progression in methotrexate-naive patients with rheumatoid arthritis and poor prognostic factors treated with abatacept: 2-year outcomes. Ann Rheum Dis. 2011;70(11): 1949-1956.

29. Roser-Page S, Vikulina T, Zayzafoon M, Weitzmann MN. CTLA-4Iginduced $\mathrm{T}$ cell anergy promotes Wnt-10b production and bone formation in a mouse model. Arthritis Rheumatol. 2014;66(4):990-999. 
30. Orsolini G, Adami G, Adami S, et al. Short-term effects of TNF inhibitors on bone turnover markers and bone mineral density in rheumatoid arthritis. Calcif Tissue Int. 2016;98(6):580-585.
31. Kume K, Amano K, Yamada S, et al. The effect of tocilizumab on bone mineral density in patients with methotrexate-resistant active rheumatoid arthritis. Rheumatology (Oxford). 2014;53(5):900-903.

\section{Publish your work in this journal}

Therapeutics and Clinical Risk Management is an international, peerreviewed journal of clinical therapeutics and risk management, focusing on concise rapid reporting of clinical studies in all therapeutic areas outcomes, safety, and programs for the effective, safe, and sustained use of medicines. This journal is indexed on PubMed Central, CAS,
EMBase, Scopus and the Elsevier Bibliographic databases. The manuscript management system is completely online and includes a very quick and fair peer-review system, which is all easy to use. Visit http://www.dovepress.com/testimonials.php to read real quotes from published authors.

Submit your manuscript here: http://www.dovepress.com/therapeutics-and-clinical-risk-management-journal 